\title{
Thermal Stress Effect on Density Changes of Hemp Hurds Composites
}

\author{
Ivana Schwarzova, Julia Cigasova, Nadezda Stevulova \\ Technical University of Košice, Slovakia \\ Civil Engineering Faculty, Institute of Environmental Engineering \\ e-mail: julia.cigasova@tuke.sk, ivana.schwarzova@tuke.sk
}

\begin{abstract}
The aim of this article is to study the behavior of prepared biocomposites based on hemp hurds as a filling agent in composite system. In addition to the filler and water, an alternative binder, called MgO-cement was used. For this objective were prepared three types of samples; samples based on untreated hemp hurds as a referential material and samples based on chemically (with $\mathrm{NaOH}$ solution) and physically (by ultrasonic procedure) treated hemp hurds. The thermal stress effect on bulk density changes of hemp hurds composites was monitored. Gradual increase in temperature led to composites density reduction of 30-40\%. This process is connected with mass loss of the adsorbed moisture and physically bound water and also with degradation of organic compounds present in hemp hurds aggregates such as pectin, hemicelluloses and cellulose. Therefore the changes in the chemical composition of treated hemp hurds in comparison to original sample and its thermal decomposition were also studied.
\end{abstract}

Key words: hemp hurds composites, lignocellulosic aggregates treatment, thermal stress

\section{Introduction}

In recent years, natural fibers, especially bast fibers (flax, hemp, jute, sisal) have been successfully used as filler and/or fiber reinforcement for composite materials. The use of building materials made from renewable resources is particularly interesting for the construction industry because using of vegetable fibers is environment-friendly and also costefficient [1]. Replacing the traditional materials is seen in use of innovative building materials in accordance with sustainable construction. Fiber reinforcement has now playing the role in composite materials (polymer and even inorganic matrices) with advantageous properties [2]. Natural plant fibers exhibit a set of important advantages, such as wide availability at relatively low cost, biorenewability, ability to be recycled, biodegradability, non-hazardous nature, zero carbon footprint, and interesting physical and mechanical properties [3]. Building materials based on natural plant fibers with inorganic binder represent a group of lightweight materials providing a healthy living in buildings [4]. 
One of the most frequently used natural plant in the construction industry is technical hemp what is the material source of different fibers types (bast fibers and woody fibers-hurds). The plant fibers nature is determined by its chemical composition. In general, celluloses in natural fibers are identified as a main structural component of the fiber. The other components of plant fibers are hemicelluloses, lignin and pectin. One of the plant fibers successful application problems is its heterogeneity and hydrophility which results in high moisture sorption of organic material. Hydroxyl groups of cellulose, hemicelluloses and lignin structure are responsible for the fibers hydrophility [5]. Moreover, their surface can be easily modified in order to have a more hydrophilic or hydrophobic character or to attach functional groups [6].

In this work, chemical ( $\mathrm{NaOH}$ solution) and physical (ultrasonic) treatments of hemp fibrous material surface are applied to hydrophility decrease and to chemical composition modification of hemp material.

For several years, the research at Department of Material Engineering of Institute of Environmental Engineering (Faculty of Civil Engineering, Technical university of Kosice) deals with study and development of biocomposites based on hemp hurds as filler and alternative binders. Basic objectives of previous research were optimization of hemp composites composition, treatment processes of hemp hurds, variation of filler/binder ratio and study durability of hardened specimens $[7,8]$. The influence of increasing temperature on monitored physic-mechanical properties of 28-days hardened composites based on untreated hemp hurds was also studied [9].

This paper deals with changes in chemical composition and thermal decomposition of treated hemp hurds in comparison with the original sample and with the effect of thermal stress on bulk density changes of composites based on treated hemp hurds in comparison to referential composites.

\section{Materials and Methods}

The original material studied in this paper is hemp hurds coming from the Netherlands Company Hempflax. Used technical hemp material consisted of a large majority of core fibers (hemp hurds, which is waste of hemp stem processing) over bast fibers, and it also contained fine dust particles originating from the manufacturing crushing process.

Original hemp hurds slices had wide particle length distribution $(8-0.063 \mathrm{~mm})$ (Fig. 1).

The mean particle length of used hemp hurds was $1.94 \mathrm{~mm}$.

Density of hemp material was $117.5 \mathrm{~kg} \cdot \mathrm{m}^{-3}$.

Average moisture content of used hemp hurds was $10.78 \%$ and it was determined by weighing the sample before and after drying in an oven at $70{ }^{\circ} \mathrm{C}$ until a constant weight.

$\mathrm{MgO}$-cement was used as a binder in the experiments and it consists of magnesium oxide obtained by high temperature decomposition of natural magnesite (CCM 85, SMZ Jelsava, Slovakia), silica sand with $97.5 \% \mathrm{SiO}_{2}$ content and mean particle diameter of $386 \mu \mathrm{m}$ (Sastin, Slovakia) and sodium hydrogen carbonate, p.a. (Gavax, Slovakia). MgO has been dry milled (laboratory vibratory mill VM 4 for $5 \mathrm{~min}$ ) in order to reduce its particle size. The mean particle diameter calculated from granulometric data was $6.85 \mu \mathrm{m}$. 


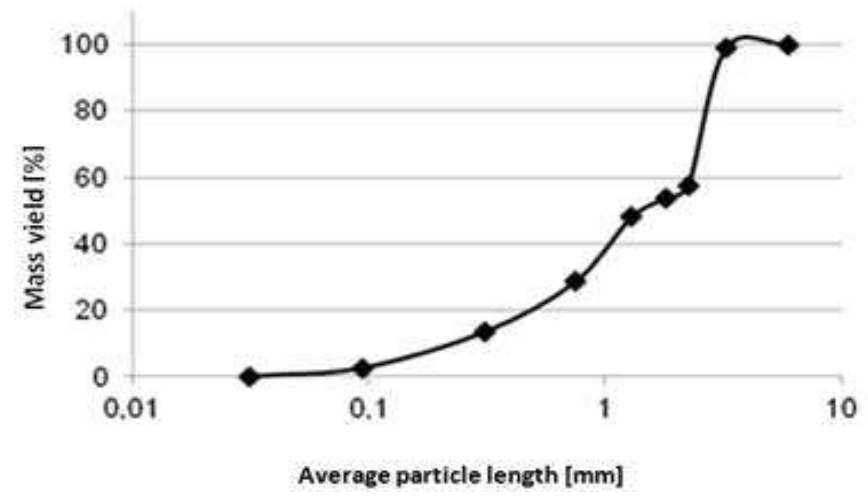

Figure 1: Hemp particle length distribution

\subsection{Treatment processes}

Before treatment processes, hemp fibers were dried at $80{ }^{\circ} \mathrm{C}$ in drying oven until a constant weight in order to ensure constant moisture content. For chemical modification, dried hemp hurds were soaked in $1.6 \mathrm{M} \mathrm{NaOH}$ solution during $48 \mathrm{~h}$ and then were neutralized in a $1 \mathrm{vol}$. $\%$ acetic acid. In order to ensure removal of chemicals excess used for treatment, prepared hemp hurds was washed with distilled water until the $\mathrm{pH}=7$. Physical modification of dried hemp samples was realized by its ultrasonication (1h). Distilled water was used as a cleaning medium and the s:1 (solid to liquid) ratio was 1:10. For hemp material ultrasonication was used an ultrasonic bath TESON 10 (Tesla, Slovakia, $50 \mathrm{~Hz}$ ).

\subsection{Chemical analysis method}

Milled and oven-dried samples were used for the determination of chemical composition of hemp hurds. Methods of hemp components determination as following: Extractives were determined in a Soxhlet apparatus with a mixture of ethanol and toluene (2:1) for $8 \mathrm{~h}$ according to the ASTM Standard D 1107-96 (1998). Total content of polysaccharides (i.e., holocellulose) was determined using the method of Wise et al. [10]. Cellulose content was determined by the Seifert method [11]. The content of hemicelluloses was determined as the difference between holocellulose and cellulose. The content of acid-insoluble (Klason) lignin was determined according to NREL procedure [12]. The samples were hydrolyzed in a twostage process. In the first stage, $72 \%(\mathrm{w} / \mathrm{w}) \mathrm{H}_{2} \mathrm{SO}_{4}$ at a temperature of $30{ }^{\circ} \mathrm{C}$ was used for 2 $\mathrm{h}$, and in the second stage, the samples were refluxed after dilution to $4 \%$ (w/w) $\mathrm{H}_{2} \mathrm{SO}_{4}$ for 4 h. Total ash content (mineral substances) was determined according to NREL procedure [13].

\subsection{Thermal decomposition analysis}

Thermo-gravimetric and differential scanning calorimetric analysis (TG/DTG) was performed using a model STA 449F3 (Netzsch, Germany) of simultaneous TG/DSC system. Thermal decomposition of the raw hemp hurds and treated samples was monitored in the standard temperature range from room temperature to $900{ }^{\circ} \mathrm{C}$ under air atmosphere, at a heating rate of $10{ }^{\circ} \mathrm{C} \mathrm{min}{ }^{-1}$. Alumina crucible $\left(\mathrm{Al}_{2} \mathrm{O}_{3}\right)$ was used in TG/DSC measurements. 


\subsection{Composites preparation}

Composites samples were prepared according to the recipe [14] illustrates in Fig. 2. The mixtures were homogenized in classical concrete mixer. Standard steel cube forms with dimensions 100x100x100 mm were used for preparation of samples in accordance with the standard STN EN 206-1/A1 [15].

The composite samples were cured for 2 days in an indoor climate. Then were removed from the forms and covered with a foil and cured under laboratory conditions during next 26 days.

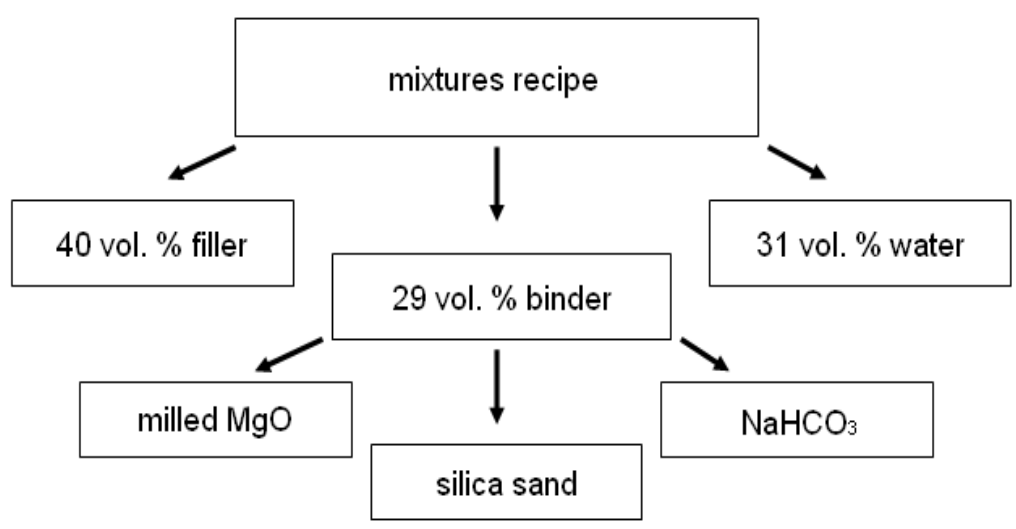

Figure 2: Scheme of mixture recipe

\subsection{Thermal stress of samples}

Prepared samples were monitored in term of bulk density changes during 28 days. All prepared hemp samples were weighed on a laboratory scales and changes of proportions were recorded (air humidity $65 \%$ ). After 28 days, the samples were thermal stressed. Initial temperature of measuring was the laboratory temperature $\left(20{ }^{\circ} \mathrm{C}\right)$. Thermal stress was performed under conditions of $100,150,180,200{ }^{\circ} \mathrm{C}$ in the laboratory oven with air circulation. Bulk density changes after thermal treatments were observed on all samples. Density was determined in accordance with standard STN EN 12390-7 [16]

\section{Results and Discussion}

\subsection{Hemp hurds chemical composition changes after treatment processes}

Changes in chemical composition of chemically and physically treated hemp hurds in comparison with the original sample are shown in Table 1. By comparing the contents of main components of hemp hurds samples, some observations have been found. According to literature data [17], no significant change in mass of ultrasonic treated hemp hurds was observed. On the other hand, the markable decrease in contents of hemicelluloses, cellulose and lignin was recorded for sample modified in $\mathrm{NaOH}$ solution. Decrease in polysaccharides component (holocellulose) is caused mainly by degradation of hemicelluloses. It is generally known, alkali treatment (with $\mathrm{NaOH}$ solution) reduces the number of hydroxyl groups of the 
amorphous materials cementing hemp hurds, destruct the cellular structure and thereby hydrophobic nature of hemp hurds increases. Some differences in reduction of lipophilic extractive compounds and ash in treated samples were measured in comparison with original sample.

Table 1: Chemical composition changes in hemp hurds before and after treatment

\begin{tabular}{|c|c|c|c|}
\hline \multirow{2}{*}{$\begin{array}{c}\text { Main components } \\
{[\%]}\end{array}$} & Original & NaOH treated & Ultrasonic treated \\
\cline { 2 - 4 } & 77.3 & 66.0 & 77.75 \\
\hline Holocellulose & 44.5 & 53.9 & 46.7 \\
\hline Cellulose & 32.8 & 12.1 & 32.6 \\
\hline Hemicelluloses & 22.0 & 27.4 & 23.23 \\
\hline Lignin & 3.5 & 2.8 & 2.6 \\
\hline $\begin{array}{c}\text { Compounds soluble } \\
\text { in toluene and } \\
\text { ethanol }\end{array}$ & 2.6 & 1.3 & 1.3 \\
\hline Ash & & & \\
\hline
\end{tabular}

\subsection{Thermal degradation of hemp hurds}

The temperature ranges of hemp hurds components decomposition in air atmospheres and the corresponding mass loss for studied samples are given in Table 2. DSC and TG/DTG curves of untreated and treated hemp hurds samples in air atmosphere are presented in Fig. 3. The DSC curves indicate three temperatures effects in which the mass loss of the organic compounds occurs.

Table 2: Temperature ranges of hemp hurds components degradation and corresponding mass losses in air atmosphere

\begin{tabular}{|c|c|c|c|c|}
\hline \multirow{2}{*}{$\begin{array}{c}\text { Hemp hurds } \\
\text { sample }\end{array}$} & \multicolumn{2}{|c|}{$\begin{array}{c}\text { Temperature ranges of components degradation in } \\
\text { air atmosphere }\left[{ }^{\circ} \mathrm{C}\right]\end{array}$} & \multirow{2}{*}{$\begin{array}{c}\text { Total mass loss } \\
{[\%]}\end{array}$} \\
\cline { 2 - 4 } Original & $1^{\text {st }}$ peak & $2^{\text {nd }}$ peak & $3^{\text {rd }}$ peak & 94.9 \\
\hline $\mathrm{NaOH}$ treated & 312 & 395 & 437 & 95.99 \\
\hline Ultrasonic treated & - & 352 & $342-382$ & 94.58 \\
\hline
\end{tabular}


DSC

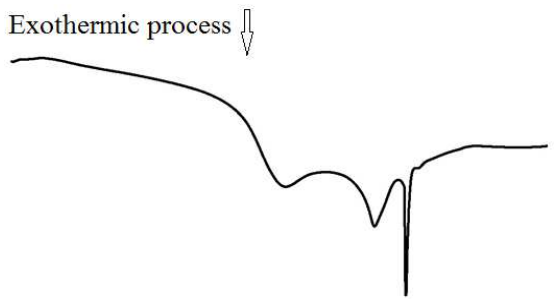

a)

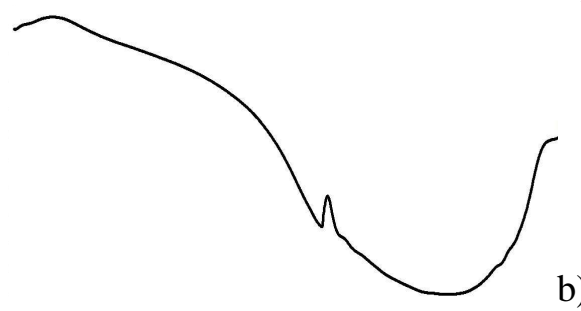

b)

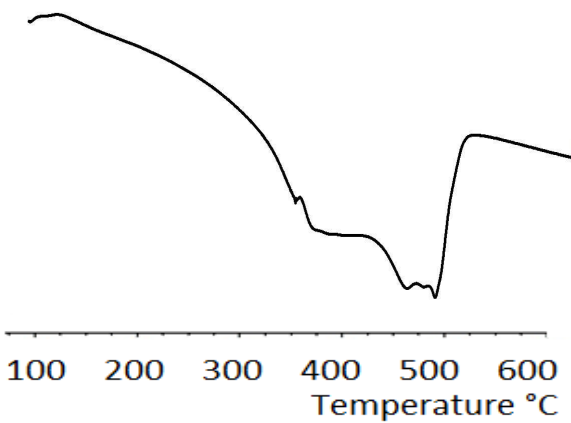

TG/DTG
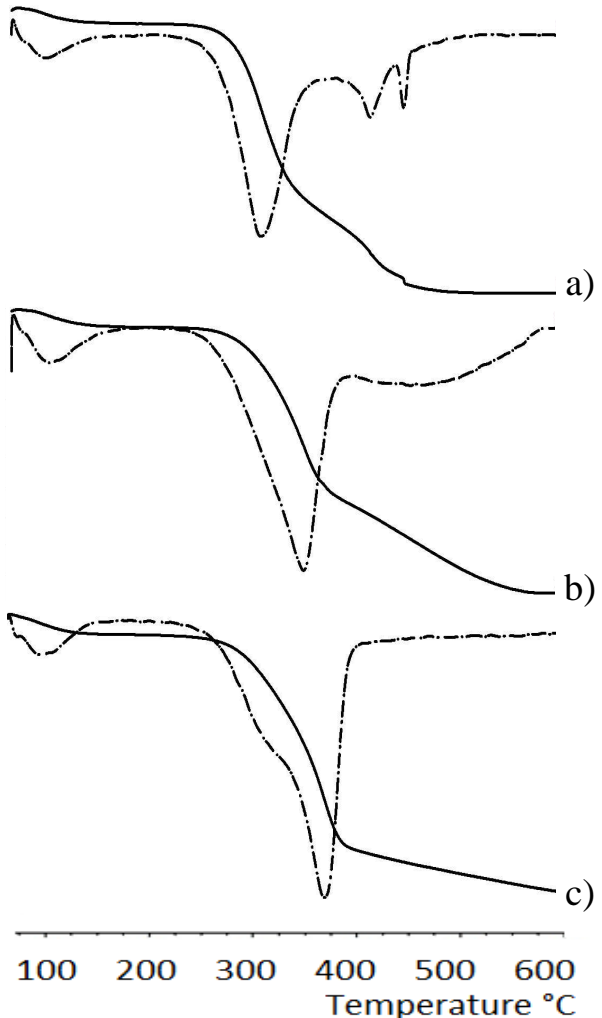

Figure 3: DSC and TG/DTG curves in air atmosphere of original (a), $\mathrm{NaOH}$ treated (b) and ultrasonic treated (c) hemp hurds samples

DSC curves of treated and untreated hemp hurds obtained by analysis in air atmosphere show an initial endothermic peak between 50 and $100{ }^{\circ} \mathrm{C}$. This $3-4 \%$ of mass loss is attributed to the evaporation of inherent air moisture and physically adsorbed water in hemp samples [18]. The DSC curve of original hemp sample showed other three exothermic peaks centred around 312, 395, and $437{ }^{\circ} \mathrm{C}$. Three peaks represent the steps of hemp hurds samples thermal degradation related to hemicelluloses, cellulose and lignin are observed. The first peak represents depolymerisation of hemicelluloses and pectin and also degradation of lignin, the second peak corresponds to decomposition of cellulose and lignin degradation and the third peak is associated with degradation of lignin. Clearly identifying the differences between main hurds components is not possible for treated samples heated in air atmosphere due to overlapping of hemicelluloses, cellulose and lignin peaks during the heating process.

\subsection{Composites bulk density changes after thermal stress}

Three types of composite samples were prepared, samples based on original hemp hurds as a referential material and samples based on chemically ( $\mathrm{NaOH}$ modified) and physically (ultrasonic (USG) modified) treated hemp hurds. The resulting values are the average of three measurements. 


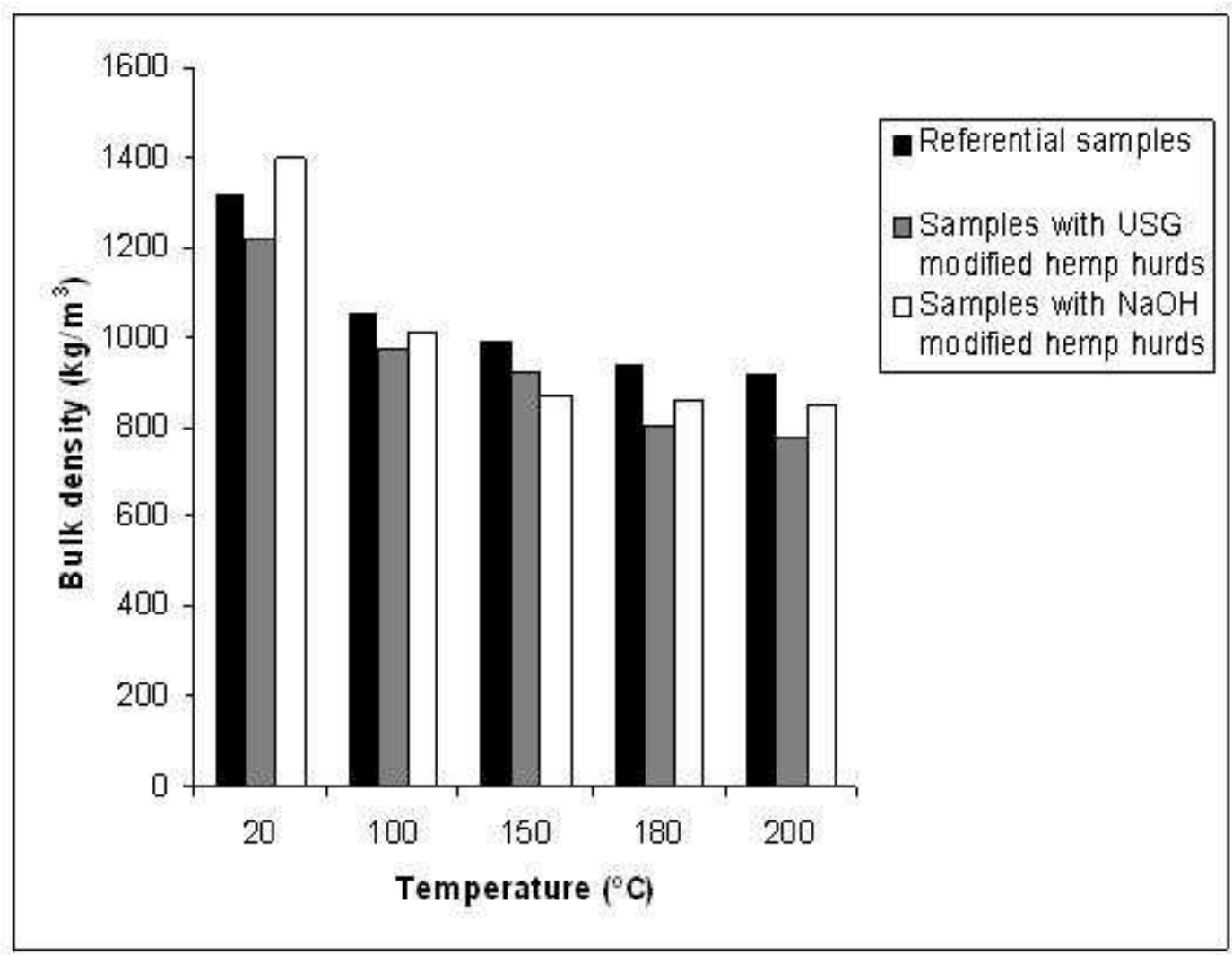

Figure 4: Changes in bulk density of composites in dependence on temperature

Fig. 4 illustrates changes in bulk density after thermal stress. A gradual decrease of bulk density was observed in the all samples. The largest decrease of bulk density values is observed for samples heated up to $100^{\circ} \mathrm{C}$. In this case, reduction in bulk density values of composites with referential and physically treated hemp material is about $20 \%$ and for composites based on chemically treated hemp hurds it is about $28 \%$. Gradual temperature increase up to $200{ }^{\circ} \mathrm{C}$ leads to reduction of bulk density about $30-40 \%$. This process is connected with mass loss of composites due to the releasing of the adsorbed moisture and/or physically bound water as well as degradation of organic compounds present in hemp hurds slices as pectin, hemicelluloses and cellulose as it was shown in the chapters 3.1. and 3.2. Morphology of composite sample after the burning of hemp hurds during thermal stress is shown in Fig.5. 


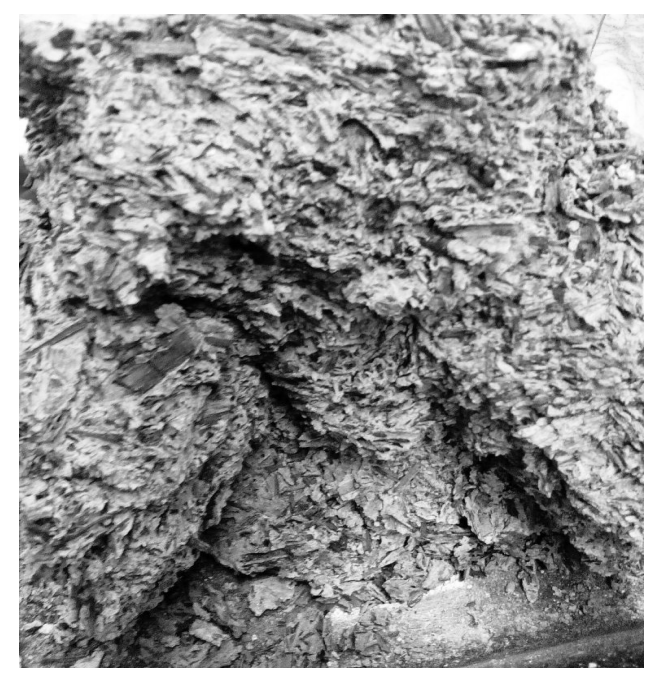

Figure 5: Hemp composite after thermal treatment

\section{Conclusion}

The present paper is devoted to chemical and physical treatment processes of hemp hurds with emphasis on the changes in chemical composition of treated hemp material in comparison with original hemp sample and its thermal decomposition and subsequent changes in density values of 28 days hardened composites based on untreated, chemically and physically treated hemp hurds with the effect of increasing thermal stress these composites samples. Alternative binding agent, $\mathrm{MgO}-$ cement, was used as a binder for all sample mixtures.

In the present paper, the effects of chemical and physical treatment procedures on the chemical composition and thermal stability changes of hemp hurds were investigated. The modification of hemp material was used for removal of organic and inorganic loosely bound contaminants from hemp hurds surface. The non-cellulosic components such as hemicelluloses, lignin and waxes were partially removed after both treatment processes. This study also monitored the impact of thermal stress on bulk density of 28 days hardened composites based on untreated and treated hemp material.

Thermal stability as one of physical parameter of hemp material was studied to assess suitability for its use as reinforcement in composite materials for building construction because hemp fibers are finding increasing use as reinforcements in composite materials. Natural fibers are heterogeneous mixtures of organic materials and thermal treatment at elevated temperatures can result in a variety of physical and chemical changes.

The decomposition onset temperature is different for different hemp samples. Studying the thermal stability of hemp samples showed some differences in their thermal degradation and also in their weight loss what corresponds with the changes in the chemical composition. Changes in mass loss are related to material evaporation and decomposition. As a result, higher thermal stability of modified hemp hurds samples due to removal of the binding constituents was observed in dependence on used treatment process. Higher thermal stability of modified samples compared to original sample indicates their improved hydrophobic nature and higher adhesion possibility with matrix. 
Decrease in bulk density values of all composite specimens was observed whereby sample prepared by using chemically treated (with $1.6 \mathrm{M} \mathrm{NaOH}$ solution) hemp hurds had the greatest decrease in bulk density and also had stable behavior after reaching $150{ }^{\circ} \mathrm{C}$. Reduction in bulk density values is connected with mass loss of composites due to release of moisture and decomposition of components present in hemp hurds.

\section{Acknowledgements}

The authors are grateful to the Slovak Grant Agency for financial support of the project VEGA1/0277/15.

\section{References}

[1] Rachini A., Le Troedec M., Peyratout C. \& Smith A. (2009). Comparison of the Thermal Degradation of Natural, Alkali-Treated and Silane-Treated Hemp Fibers Under Air and an Inert Atmosphere. Journal of Applied Polymer Science. 112, 226-234. DOI 10.1002/app.29412.

[2] Azwa Z.N., Yousif B.F., Manalo A.C. \& Karunasena W. (2013). A review on the degradability of polymeric composites based on natural fibres. Materials and Design. 47, 424-442.

[3] Satyanarayana K.G., Arizaga G.G.C. \& Wypych F. (2009). Biodegradable composites based on lignocellulosic fibers-an overview. Progress in Polymere Science. 34, 982-1021.

[4] Preikss I., Skujans J., Adamovics A. \& Iljins U. (2013). Evaluation of hemp (Cannabis Sativa L.) quality parameters for building materials from foam gypsum products. Chemical Engineering Transactions. 32, 1639-44.

[5] Sreekala M.S., Kumaran M.G., Joseph S. \& Jacob M. (2000). Oil palm fiber reinforced phenol formaldehyde composites: Influence of fiber surface modifications on the mechanical performance. Applied Composite Materials. vol. 7, 295-329.

[6] Faruk O., Bledzki A.K., Fink H.P. \& Sain M. (2012). Biocomposites reinforced with natural fibres: 2000-2010. Progress in Polymer Science. vol. 37, 1552-1596.

[7] Cigasova J., Stevulova N., Sicakova A. \& Junak J. (2013). Some aspects of lightweight composites durability. Chemical Engineering Transactions. 32, 1615-1620.

[8] Stevulova N., Cigasova J., Purcz P., Schwarzova I., Kacik F. \& Geffert A. (2015). Water Absorption Behavior of Hemp Hurds Composites. Materials. 8 (5), 2243-2257.

[9] Kidalova L., Terpakova E., Priganc S. \& Stevulova N. (2011). Possibilities of using hemp shives in light-weight composites. In Conference CEST 2011: 12th international conference on environmental science and technology, September 2011 (547-B-552). Rhodes, Greece: GlobalNEST.

[10] Wise L.E., Maxine M. \& D'Addieco A.A. (1946). Chlorite holocellulose, its fractionation and bearing on summative wood analysis and on studies on the hemicelluloses. Paper Trade J. 122, $35-43$.

[11] Seifert V.K. (1956). Über ein neues Verfahren zur Schnellbestimmung der Rein-Cellulose. Papier. 10, 301-306.

[12] Sluiter A., Hames B., Ruiz R., Scarlata C., Sluiter J., Templeton D. \& Crocker D. (2010) . Determination of structural carbohydrates and lignin in biomass. Technical Report NREL/TP510-42618. National Renewable Energy Laboratory: Golden. CO. USA. 
[13] Sluiter A., Hames B., Ruiz R., Scarlata C., Sluiter J. \& Templeton D. (2008). Determination of ash in biomass. Technical Report NREL/TP-510-42622. National Renewable Energy Laboratory: Golden. CO. USA.

[14] Bydzovsky J. (2009). Utilization of fast renewable raw materials in building products. In 12th International Scientific Conference, 2009 (43-46). Brno,Czech republic: Brno Technical University.

[15] STN EN 206-1/A1. (2009). Concrete Part 1. Specification, performance, production and conformity.

[16] STN EN 12390-7. (2011). Testing hardened concrete. Part 7. Density of hardened concrete.

[17] Renouard S., Hano C., Doussot J., Blondeau J.P. \& Lainé E. (2014). Characterization of ultrasonic impact on coir, flax and hemp fibers. Materials Letters. 129, 137-141.

[18] Quajai S. \& Shanks R.A. (2005). Composition, structure and thermal degradation of hemp cellulose after chemical treatments. Polym Degrad Stab. 89, 327-335. 